\title{
Destressing yeast for higher biofuel yields: Can excess chaotropicity be mitigated?
} --Manuscript Draft--

Manuscript Number:

Full Title:

Article Type:

Keywords:

Corresponding Author:
ABAB-D-20-00472R1

Destressing yeast for higher biofuel yields: Can excess chaotropicity be mitigated?

Commentary

Bioethanol; kosmotropicity; chaotropicity; fermentation; biofuel yield; bioenergy

David J Timson

University of Brighton

Brighton, UNITED KINGDOM

Corresponding Author Secondary Information:

Corresponding Author's Institution:

University of Brighton

Corresponding Author's Secondary Institution:

First Author:

David J Timson

First Author Secondary Information:

Order of Authors:

David J Timson

Joshua Eardley

Order of Authors Secondary Information:

Funding Information:

University of Brighton

Mr Joshua Eardley

\section{Additional Information:}

Question

Response

Please select a section/category for your manuscript.

Biofuels and Biochemicals from Renewable Bioresources - Renewable feedstocks, especially the non-food biomass resources. The section includes novel microbes, enzymes, processes involved in the production of biofuels and biochemicals from renewable bioresources with the focus on non-food biomass resources.

Abstract:

Biofuels have the capacity to contribute to carbon dioxide emission reduction and to energy security as oil reserves diminish and/or become concentrated in politically unstable regions. However, challenges exist in obtaining the maximum yield from industrial fermentations. One challenge arises from the nature of alcohols. These compounds are chaotropic (i.e. causes disorder in the system) which causes stress in the microbes producing the biofuel. Brewer's yeast ( Saccharomyces cerevisiae ) typically cannot grow at ethanol concentration much above $17 \%(\mathrm{v} / \mathrm{v})$. Mitigation of these properties has the potential to increase yield. Previously, we have explored the effects of chaotropes on model enzyme systems and attempted (largely unsuccessfully) to offset these effects by kosmotropes (compounds which increase the order of the system, i.e. the "opposite" of chaotropes). Here we present some theoretical results which suggest that high molecular mass polyethylene glycols may be the most effective kosmotropic additives in terms of both efficacy and cost. The assumptions and limitations of these calculations are also presented. A deeper understanding of the effects of chaotropes on biofuel-producing microbes is likely to inform improvements in bioethanol yields and enable more rational approaches to the "neutralisation" of chaotropicity. 
Reviewer \#1: 1、The references were not numbered in the order they appear. For example, references 1 and 2 first appeared in the fourth paragraph of the text. Reference $(15,24,25)$ appears in the 'Introduction' section.

We apologise for this error and have now used the correct endnote template.

2. The language in the text needs to be carefully polished.

We have read the paper carefully and made a number of corrections.

3. The title of the article should be further specified.

We agree. The title has been changed to "Destressing yeast for higher biofuel yields: Can excess chaotropicity be mitigated?"

4. The paragraph structure of the article is suggested to be adjusted. For example, the author mainly talked about 'chaotropes' and 'kosmotropes', and glycerol does not belong to the typical 'chaotropes' or 'kosmotropes'. It seems to be incompatible as a paragraph 'The problem with glycerol 'alone.

We agree. We have amalgamated this short section into the preceding one.

5. The authors mentions that'Bioethanol fermentations have a theoretical maximum yield of around $17 \%(\mathrm{v} / \mathrm{v})$ ethanol $(17,30)^{\prime}$. It seems that $20 \%(\mathrm{v} / \mathrm{v})$ has been reached, please refer to the article [30] in your reference list.

We thank the reviewer for this valid point. We have modified the text accordingly.

"Bioethanol fermentations have a theoretical maximum yield of around $17 \%(\mathrm{v} / \mathrm{v})$ ethanol, under conditions similar to those used industrially (i.e. around $30^{\circ} \mathrm{C}$ ). Yields of up to $20 \%(\mathrm{v} / \mathrm{v}$ ) in sake fermentations which are carried out at low temperatures, over extended periods of time and with specially selected yeast strains."

6. The author present some theoretical results which suggest that high molecular mass polyethylene glycols may be the most effective kosmotropic additives in terms of both efficacy and cost. It is recommended to state the effect of adding PEG (such as 0.023 M PEG6000) on the growth of Saccharomyces cerevisiae itself and ethanol fermentation.

The referee raises a valid point. High molecular mass PEGs may exert osmotic effects on cells. We have added a sentence to note this.

"However, high molecular mass PEGs may exert osmotic effects on the yeast cells which may reduce growth rates and ethanol yields. Experimental testing of these additives is recommended."

7. The author states that it may be possible to regulate the chaotropicity by addition of kosmotropic solutes. It is recommended that the author list a table to clearly show that the mitigation of product chaotropicity by provision of exogenous kosmotropic substances in others' research works.

We think this is an excellent idea and have incorporated this as new table 1. 
8. Due to the presence of various inhibitors, the concentration of ethanol is often not high in the production of cellulosic ethanol. Do these inhibitors also have chaotropicity? Will they interfere with the use of kosmotropic additives?

The reviewer raises an important point. While sugars such as glucose are relatively "neutral" on the chaotropicity scale, some other compounds which may be present (e.g. phenols and vanillin) are chaotropic. We have noted this in the paper.

"Although fermentation substrates, typically sugars such as glucose and sucrose, are relatively "neutral" on the chaotropicity scale, other compounds which may be present in feedstocks (e.g. phenols and vanillin) are chaotropic. The presence of these additional chaotropes may need to be considered in any mitigation strategy." 


\section{Commentary:}

Destressing yeast for higher biofuel yields: Can excess chaotropicity be mitigated?

David J. Timson* and Joshua Eardley,

School of Pharmacy and Biomolecular Sciences, University of Brighton, Huxley Building, Lewes Road, Brighton, BN2 4GJ. UK.

*Corresponding author: School of Pharmacy and Biomolecular Sciences, University of Brighton, Huxley Building, Lewes Road, Brighton, BN2 4GJ. UK

d.timson@brighton.ac.uk

Footnote: This commentary is based in part on a presentation given at The International Conference on Energy and Sustainable Futures (ICESF), Nottingham, UK, in September 2019. 


\begin{abstract}
Biofuels have the capacity to contribute to carbon dioxide emission reduction and to energy security as oil reserves diminish and/or become concentrated in politically unstable regions. However, challenges exist in obtaining the maximum yield from industrial fermentations. One challenge arises from the nature of alcohols. These compounds are chaotropic (i.e. causes disorder in the system) which causes stress in the microbes producing the biofuel. Brewer's yeast (Saccharomyces cerevisiae) typically cannot grow at ethanol concentration much above $17 \%(v / v)$. Mitigation of these properties has the potential to increase yield. Previously, we have explored the effects of chaotropes on model enzyme systems and attempted (largely unsuccessfully) to offset these effects by kosmotropes (compounds which increase the order of the system, i.e. the "opposite" of chaotropes). Here we present some theoretical results which suggest that high molecular mass polyethylene glycols may be the most effective kosmotropic additives in terms of both efficacy and cost. The assumptions and limitations of these calculations are also presented. A deeper understanding of the effects of chaotropes on biofuel-producing microbes is likely to inform improvements in bioethanol yields and enable more rational approaches to the "neutralisation" of chaotropicity.
\end{abstract}

Keywords: Bioethanol; kosmotropicity; chaotropicity; fermentation; biofuel yield; bioenergy 


\section{Introduction}

Biofuels have the potential to replace fossil fuels in many applications. They offer considerable environmental advantages over fossil fuels since they are truly renewable and have lower overall net carbon dioxide emissions. Since the normal precursors are either crop plants or organic waste, these can be produced locally reducing the need to transport fuels over long distances. This has consequent benefits for the environment, the cost of the fuel and for energy security [1-3]. However, there are several problems with biofuels which may prevent their more widespread adoption. The reliance on crop plants means that there is the potential for competition between food and fuel uses of crops and the land used to produce them $[1,4]$. There are also several challenges in achieving high yields. These relate, in part, to difficulties in digesting some plant matter, notably celluloses and lignins $[1,5]$. This means that a substantial fraction of the carbon in the plants is not readily converted to fuel. The fuels themselves often inhibit their own biosynthesis, by "poisoning" the microbes which are producing them. This "toxic" effect has a variety of causes; a key issue is the chaotropicity of compounds commonly used as biofuels, e.g. ethanol and butanol[6] . This is recognised as a significant, limiting factor in maximising biofuel yields [7]. However, to improve the environmental and economic attractiveness of biofuels, yields need to rise. This commentary focusses on the mitigation of chaotropicity in the production of ethanol by the baker's or brewer's yeast, Saccharomyces cerevisiae. Many of the issues considered will also apply to other biofuel fermentation processes.

\section{Chaotropes and kosmotropes of relevance to biofuel fermentations}

Chaotropes are compounds which increase the overall entropy of a solution [8]. This has particular relevance in biology since this results in the disordering and unfolding of macromolecules and the disruption of biological membranes $[9,10]$. Since cells rely on membranes to define their various compartments and biological macromolecules depend on their three-dimensional conformations for their correct activities and functions, chaotropes often cause generalised, non-specific toxicity to living systems. The molecular basis of chaotropicity remains uncertain, somewhat controversial and may vary with the chaotrope and the system being disrupted [11]. Chaotropes cause disruption of the hydrophobic interactions which stabilise 
proteins, DNA and membranes. This is partly due to the increased system entropy reducing the entropic penalty for exposing hydrophobic residues to the bulk water and may also result from specific interactions between the chaotropic molecule and functional groups within the macromolecule $[8,12]$. Kosmotropes have the opposite effects. They reduce solution entropy and promote the ordering and rigidification of biological macromolecules.

The quantification of chaotropicity has not been straightforward. Given the links to entropic changes, entropies of solvation often correlate with the effects observed on phenomena such as protein stability [8]. However, the most extensive quantitative scale of chaotropicity available to date is based on an empirical measure, changes to the gelling temperature of agar. This scale can be used with almost any water-soluble compound and has been applied to salts, small organic molecules and macromolecules such as (poly)ethylene glycol (PEG). It spans a wide range of values of chaotropicity (positive) and kosmotropicity (negative). Values around zero are considered to be “neutral" [8].

The products of biofuel fermentations are typically chaotropic, for example ethanol (molar chaotropicity $\left.5.93 \mathrm{~kJ} \mathrm{~kg}^{-1} \mathrm{~mol}^{-1}\right)$ and butanol $\left(37.4 \mathrm{~kJ} \mathrm{~kg}^{-1} \mathrm{~mol}^{-1}\right)$. Although fermentation substrates, typically sugars such as glucose and sucrose, are relatively "neutral" on the chaotropicity scale, other compounds which may be present in feedstocks (e.g. phenols and vanillin) are chaotropic [8]. The presence of these additional chaotropes may need to be considered in any mitigation strategy [7]. Microbial cells naturally mitigate the effects of chaotropicity by producing compatible solutes, many of which are kosmotropes. These include trehalose (molar chaotropicity, $\left.10.6 \mathrm{~kJ} \mathrm{~kg}^{-1} \mathrm{~mol}^{-1}\right)$, betaine $\left(-25.5 \mathrm{~kJ} \mathrm{~kg}^{-1} \mathrm{~mol}^{-1}\right)$, proline $\left(-5.8 \mathrm{~kJ} \mathrm{~kg}^{-1} \mathrm{~mol}^{-1}\right)$ and glycerol (1.1 $\mathrm{kJ} \mathrm{kg}^{-1} \mathrm{~mol}^{-1}$ ) [8]. This raises the interesting hypothesis that it may be possible to regulate the chaotropicity of biofuel fermentations by the addition of kosmotropic solutes. This would be analogous to the regulation of the $\mathrm{pH}$ in fermentations by the addition of acids and bases. Ideally it would be possible to predict the effects of kosmotrope addition (just as it is with acid/base addition). To do this, it is necessary to 
understand how to calculate the net chaotropicity of a mixture of chaotropic and kosmotropic compounds.

Although glycerol is commonly produced by microbes as a compatible solute, it is not a kosmotrope. On the agar gel point scale, it is close to "neutral" at moderate concentrations $(<5 \mathrm{M})$ and more chaotropic at higher concentrations [8]. This suggests that its mode of action is not through the direct "neutralisation" of chaotropicity, but perhaps through more direct interactions which stabilise biological macromolecules. It also suggests that its chaotropicity is not a linear function of its concentration. While this effect has not been observed with other compounds, the limited state of our knowledge means that this possibility cannot be ruled out. Non-linear relationships between concentration and chaotropicity would considerably complicate any calculations of net chaotropicity and thus the practicalities and economics of applying this in commercial biofuel fermentations.

\section{Quantification of chaotropicity - some assumptions and conclusions of relevance to biofuels}

When calculating net chaotropicities, we made two initial assumptions. First, we assumed that there is a linear relationship between chaotropicity and concentration. This means that the chaotropicity of any concentration of a compound can be readily calculated from the molar chaotropicity. We also assumed that chaotropicities (and kosmotropicities) are additive. In other words, if we have two compounds in solution, with one compound contributing a chaotropicity of $\mathrm{X} \mathrm{kJ} \mathrm{kg}^{-1}$ and the other $\mathrm{Y} \mathrm{kJ} \mathrm{kg-1}$, the net solution chaotropicity should be $\mathrm{X}+\mathrm{Y} \mathrm{kJ} \mathrm{kg}{ }^{-1}$. This follows from the assumption of linearity of the relationship between chaotropicity and concentration. It is based on an underlying assumption that the molecular mechanism of chaotropicity is essentially the same for all compounds. It also assumes no significant interactions between the two types of molecule in solution which might affect their chaotropic effects.

Bioethanol fermentations have a theoretical maximum yield of around $17 \%(\mathrm{v} / \mathrm{v})$ ethanol, under conditions similar to those used industrially (i.e. around $30^{\circ} \mathrm{C}$ ) $[13,14]$. Yields of up 
to $20 \%(\mathrm{v} / \mathrm{v})$ in sake fermentations which are carried out at low temperatures, over extended periods of time and with specially selected yeast strains [15]. At these concentrations yeast cells cease to function, partly due to the chaotropicity of ethanol. However, actual yields are typically lower, for example [16-22]. Yeast cells are remarkably well adapted to functioning in relatively high ethanol concentrations compared to most microbes $[3,23,24]$. Thus, $S$. cerevisiae can be classified as a zymogenous species, i.e. one which grows well on substrates which are readily available in the environment and easily metabolised [25-27]. Recent work has suggested that stress should not always be considered harmful for microbes since it drives vitality and genetic diversity $[28,29]$. Thus, it is possible to select for strains with higher ethanol tolerance [3]. Fermentation processes can be designed to mitigate stress. For example, temperature and $\mathrm{pH}$ can be carefully controlled, excess ethanol can be removed, and growth media optimised [30]. We propose that chaotropicity mitigation may also be helpful and we summarise some examples of this in table 1.

Table 1: Examples of the mitigation of chaotropicity by kosmotropes

\begin{tabular}{|l|l|l|l|}
\hline Chaotrope & Kosmotrope & Comments & References \\
\hline Urea & Trimethylamine $N-$ & Used by \\
oxide & $\begin{array}{l}\text { elasmobranch fish } \\
\text { to mitigate the toxic } \\
\text { effects of urea. }\end{array}$ & {$[31]$} \\
\hline Urea & $\begin{array}{l}\text { Betaine or } \\
\text { ammonium }\end{array}$ & $\begin{array}{l}\text { Partially mitigate } \\
\text { effects on yeast } \\
\text { sulphate }\end{array}$ & $\begin{array}{l}\text { growth in a } \\
\text { laboratory study. }\end{array}$ \\
\hline Ethanol & Trehalose & $\begin{array}{l}\text { Produced by many } \\
\text { microorganisms, } \\
\text { including yeast to } \\
\text { mitigate chaotrope } \\
\text { stress. }\end{array}$ & {$[33,34]$} \\
& & & \\
\hline
\end{tabular}




\begin{tabular}{|c|c|c|c|}
\hline Ethanol & Ectoine & $\begin{array}{l}\text { Partially mitigates } \\
\text { chaotropicity in } \\
\text { fermentations by } \\
\text { Zymomonas } \\
\text { mobilis. }\end{array}$ & {$[35]$} \\
\hline Ethanol & Proline & $\begin{array}{l}\text { Mitigates } \\
\text { chaotropic stress in } \\
\text { many } \\
\text { microorganisms, } \\
\text { including yeast. }\end{array}$ & {$[36]$} \\
\hline tert-Butyl alcohol & $\begin{array}{l}\text { Trimethylamine } N \text { - } \\
\text { oxide }\end{array}$ & $\begin{array}{l}\text { Chaotropicity } \\
\text { "neutralised" in } \\
\text { theoretical and } \\
\text { laboratory studies. }\end{array}$ & {$[37,38]$} \\
\hline Butanol & Proline & $\begin{array}{l}\text { Engineering Bacillus } \\
\text { subtilis } 168 \text { to } \\
\text { increase proline } \\
\text { production } \\
\text { increased butanol } \\
\text { yield. }\end{array}$ & [39] \\
\hline
\end{tabular}

A concentration of ethanol of $17 \%(v / v)$ is equal to a molar concentration of $2.9 \mathrm{M}$ and, therefore, to a solution chaotropicity of $17.2 \mathrm{~kJ} \mathrm{~kg}^{-1}$. To return this value to "neutral" would, assuming that chaotropicities are additive, require the addition of a kosmotropic compound at a concentration which has a chaotropicity of $-17.2 \mathrm{~kJ} \mathrm{~kg}^{-1}$. This could be achieved by adding $0.26 \mathrm{M}$ ammonium sulphate, $0.68 \mathrm{M}$ betaine, $2.9 \mathrm{M}$ proline, $1.1 \mathrm{M}$ PEG 200, 0.14 M PEG 1000 or 0.023 M PEG 6000. However, experimental investigations suggest that the situation is more complex. Attempts to offset the chaotropic effects of alcohols on the enzyme $\beta$-galactosidase were largely unsuccessful. Indeed, when used on their own, all of the kosmotropes tested also inhibited the enzyme to similar extents 
to the chaotropic alcohols [40]. Similar results have been obtained in a yeast model in which the effects of chaotropes, kosmotropes and mixtures thereof on growth were tested [32]. Other studies also question the additivity of chaotropicities in real biological situations, for example [41-44]. These all demonstrate complex relationships where the chaotropicites of mixtures were measured directly using the agar gelation method. Nevertheless, these studies also broadly support the hypothesis that kosmotropes can offset the detrimental effects of chaotropes. Unfortunately, in a yeast model, while the effects of urea could be partially offset by ammonium sulphate and betaine, no equivalent effects were observed with ethanol [32]. The reasons for this difference are currently unknown.

\section{The economics of kosmotrope addition}

If kosmotropes are to be added to biofuel fermentations, it will need to be economically as well as scientifically viable. There would be little point in adding expensive, additional reagents for a marginal increase in yield. This means that we need to consider the cost per unit kosmotropicity (Table 2). This calculation suggests that ammonium sulphate or PEG 6000 would be the best additives to consider in commercial fermentations. Given that ammonium sulphate addition would raise the ionic strength of the fermentation mix, the use of electrically neutral PEG might be preferred. However, high molecular mass PEGs may exert osmotic effects on the yeast cells, which may reduce growth rates and ethanol yields. Experimental testing of these additives is recommended. It should be noted that this calculation is based on current prices (with no allowance for commercial pricing or deals for large orders) and further assumes (unrealistically) that prices would be unchanged in the event of considerably increased demand for a compound from the biofuel industry. Nevertheless, the rankings presented here are likely to be broadly correct.

Table 2: Some costs per unit kosmotropicty of compounds of relevance to the biofuel industry

\section{Compound}

Molar chaotropictya

$\mathrm{kJ} \mathrm{kg}^{-1} \mathrm{~mol}^{-1}$
Cost per unit kosmotropicity

(f per kJ kg-1 $\mathrm{mol}^{-1}$ ) 


\begin{tabular}{lll}
\hline Betaine & -25.5 & 0.58 \\
Proline & -5.8 & 11.35 \\
Trehalose & -10.6 & 46.89 \\
Ammonium sulphate & -66.9 & 0.14 \\
PEG 200 & -15.0 & 0.84 \\
PEG 1000 & -126 & 0.29 \\
PEG 6000 & -659 & 0.16 \\
\hline
\end{tabular}

Notes:

a Values from ref [8]; a negative value for chaotropicity represents a kosmotropic compound.

b Prices from Sigma-Aldrich price list (www.sigmaaldrich.com/catalog/) as of $28^{\text {th }}$ April 2019.

\section{6. (Currently) unanswered questions}

In addition to the problems noted above with the quantification of mixtures of chaotropes and kosmotropes, there are some other areas which require further elucidation. A greater understanding of the molecular basis of chaotropicity and kosmotropicity is required from experimental and in silico studies. The mode of action of glycerol also requires greater understanding. How ethanol's chaotropic properties interact with its mildly hydrophobic properties needs to be explained.

Critically a fuller understanding the relationship between chaotropicity and concentration is required along with robust methods to estimate net chaotropicity of mixtures. While thermodynamic properties (e.g. enthalpy and entropy) are additive, some other chemical properties are not. For example, while the $\mathrm{pH}$ of mixtures can be predicted using $\mathrm{pK}_{\mathrm{a}}$ values and concentrations, $\mathrm{pH}$ values are not additive. Alternatively, a method to measure the net solution chaotropicity experimentally would circumvent the need for calculating this value. This would require the invention of a chaotropicity meter, analogous to instruments which measure $\mathrm{pH}$ or ionic strength. No such instrument has been designed, but it would need to be reusable in order to be economically attractive to the biofuel industry. The agar gel point method covers a wide range of chao- and kosmotropicity values and is applicable to different types of 
compounds [8]. However, as currently implemented, it is not reusable because the solution being tested is mixed with the agar. Therefore, a completely new method may be required (e.g. one based on the unfolding/folding of a protein, or a biophysical measurement such as nanorheology [45]).

\section{Conclusion}

There is scope to use kosmotropes as additives to mitigate the chaotropic effects observed in biofuel fermentation. However, much greater understanding of the mechanism of chaotropicity and the quantification of this phenomenon is required before this can be done rationally. Until then, it may be possible to develop empirical, "trial and error" methods which are specific to individual fermentation conditions.

\section{Acknowledgments}

JE thanks the University of Brighton and the Universities Alliance Doctoral Training Alliance for a PhD studentship. DJT acknowledges his long-standing collaboration with Dr John E Hallsworth (Queen's University, Belfast, UK) who first encouraged him to think about problems of chaotropicity in cellular systems. We thank Dr Samantha Banford for her assistance with the revised version of this paper. 


\section{References}

1. das Neves MA, Kimura T, Shimizu N, Nakajima M (2007) State of the art and future trends of bioethanol production. Dynam Biochem Proc Biotechnol Mol Biol 1 (1):1-14

2. Mohd Azhar SH, Abdulla R, Jambo SA, Marbawi H, Gansau JA, Mohd Faik AA, Rodrigues KF (2017) Yeasts in sustainable bioethanol production: A review. Biochem Biophys Rep 10:52-61. doi:10.1016/j.bbrep.2017.03.003

3. Paulino de Souza J, Dias do Prado C, Eleutherio ECA, Bonatto D, Malavazi I, Ferreira da Cunha A (2018) Improvement of Brazilian bioethanol production - Challenges and perspectives on the identification and genetic modification of new strains of Saccharomyces cerevisiae yeasts isolated during ethanol process. Fungal Biol 122 (6):583-591. doi:10.1016/j.funbio.2017.12.006

4. Banerjee A (2011) Food, feed, fuel: transforming the competition for grains. Dev Change 42 (2):529-557

5. Prasad RK, Chatterjee S, Mazumder PB, Gupta SK, Sharma S, Vairale MG, Datta S, Dwivedi SK, Gupta DK (2019) Bioethanol production from waste lignocelluloses: A review on microbial degradation potential. Chemosphere 231:588-606. doi:10.1016/j.chemosphere.2019.05.142 6. Timson DJ (2020) The roles and applications of chaotropes and kosmotropes in industrial fermentation processes. World J Microbiol Biotechnol 36 (6):89. doi:10.1007/s11274-020-02865-8 7. Cray JA, Stevenson A, Ball P, Bankar SB, Eleutherio EC, Ezeji TC, Singhal RS, Thevelein JM, Timson DJ, Hallsworth JE (2015) Chaotropicity: a key factor in product tolerance of biofuel-producing microorganisms. Curr Opin Biotechnol 33:228-259. doi:10.1016/j.copbio.2015.02.010

8. Cray JA, Russell JT, Timson DJ, Singhal RS, Hallsworth JE (2013) A universal measure of chaotropicity and kosmotropicity. Environ Microbiol 15 (1):287-296. doi:10.1111/1462-2920.12018 9. Bennion BJ, Daggett V (2003) The molecular basis for the chemical denaturation of proteins by urea. Proc Natl Acad Sci U S A 100 (9):5142-5147. doi:10.1073/pnas.0930122100 10. Das A, Mukhopadhyay C (2009) Urea-mediated protein denaturation: a consensus view. J Phys Chem B 113 (38):12816-12824. doi:10.1021/jp906350s

11. Ball P, Hallsworth JE (2015) Water structure and chaotropicity: their uses, abuses and biological implications. Phys Chem Chem Phys 17 (13):8297-8305. doi:10.1039/c4cp04564e 12. Salvi G, De Los Rios P, Vendruscolo M (2005) Effective interactions between chaotropic agents and proteins. Proteins 61 (3):492-499. doi:10.1002/prot.20626

13. Duitama J, Sánchez-Rodríguez A, Goovaerts A, Pulido-Tamayo S, Hubmann G, Foulquié-Moreno MR, Thevelein JM, Verstrepen KJ, Marchal K (2014) Improved linkage analysis of Quantitative Trait Loci using bulk segregants unveils a novel determinant of high ethanol tolerance in yeast. BMC Genomics 15 (1):207. doi:10.1186/1471-2164-15-207

14. Swinnen S, Schaerlaekens K, Pais T, Claesen J, Hubmann G, Yang Y, Demeke M, Foulquié-Moreno MR, Goovaerts A, Souvereyns K, Clement L, Dumortier F, Thevelein JM (2012) Identification of novel causative genes determining the complex trait of high ethanol tolerance in yeast using pooledsegregant whole-genome sequence analysis. Genome Res 22 (5):975-984.

doi:10.1101/gr.131698.111

15. Wu H, Zheng X, Araki Y, Sahara H, Takagi H, Shimoi H (2006) Global gene expression analysis of yeast cells during sake brewing. Appl Environ Microbiol 72 (11):7353-7358. doi:10.1128/aem.0109706

16. Cheng N, Koda K, Tamai Y, Yamamoto Y, Takasuka TE, Uraki Y (2017) Optimization of simultaneous saccharification and fermentation conditions with amphipathic lignin derivatives for concentrated bioethanol production. Bioresource Technology 232:126-132.

doi:https://doi.org/10.1016/j.biortech.2017.02.018

17. El-Dalatony MM, Kurade MB, Abou-Shanab RAI, Kim H, Salama E-S, Jeon B-H (2016) Long-term production of bioethanol in repeated-batch fermentation of microalgal biomass using immobilized Saccharomyces cerevisiae. Bioresource Technology 219:98-105.

doi:https://doi.org/10.1016/j.biortech.2016.07.113 
18. Shadbahr J, Khan F, Zhang Y (2017) Kinetic modeling and dynamic analysis of simultaneous saccharification and fermentation of cellulose to bioethanol. Energy Conversion and Management 141:236-243. doi:https://doi.org/10.1016/i.enconman.2016.08.025

19. Guerrero AB, Ballesteros I, Ballesteros M (2018) The potential of agricultural banana waste for bioethanol production. Fuel 213:176-185. doi:https://doi.org/10.1016/j.fuel.2017.10.105

20. Zeng G, You H, Wang K, Jiang Y, Bao H, Du M, Chen B, Ai N, Gu Z (2019) Semi-simultaneous Saccharification and Fermentation of Ethanol Production from Sargassum horneri and Biosorbent Production from Fermentation Residues. Waste and Biomass Valorization:1-13

21. Jugwanth Y, Sewsynker-Sukai Y, Gueguim Kana EB (2020) Valorization of sugarcane bagasse for bioethanol production through simultaneous saccharification and fermentation: Optimization and kinetic studies. Fuel 262:116552. doi:https://doi.org/10.1016/i.fuel.2019.116552

22. Chang Y-H, Chang K-S, Chen C-Y, Hsu C-L, Chang T-C, Jang H-D (2018) Enhancement of the Efficiency of Bioethanol Production by Saccharomyces cerevisiae via Gradually Batch-Wise and FedBatch Increasing the Glucose Concentration. Fermentation 4 (2):45

23. Rangel DEN, Finlay RD, Hallsworth JE, Dadachova E, Gadd GM (2018) Fungal strategies for dealing with environment- and agriculture-induced stresses. Fungal Biology 122 (6):602-612.

doi:https://doi.org/10.1016/i.funbio.2018.02.002

24. Cray JA, Bell AN, Bhaganna P, Mswaka AY, Timson DJ, Hallsworth JE (2013) The biology of habitat dominance; can microbes behave as weeds? Microb Biotechnol 6 (5):453-492. doi:10.1111/17517915.12027

25. Winogradsky S (1924) Sur la microflora autochtone de la terre arable. Comptes rendus hebdomadaires des seances de l'Academie des Sciences (Paris) D 178:1236-1239

26. Winogradsky S (1949) Microbiologie du sol: problemes et methodes. Cinquante ans de recherches. Masson,

27. Atlas RM, Bartha R (1987) Microbial ecology: fundamentals and applications. The Benjamim. Cummings Publ., Menlo Park.

28. Aertsen A, Michiels CW (2005) Diversify or die: generation of diversity in response to stress. Critical reviews in microbiology 31 (2):69-78

29. Hallsworth JE (2018) Stress-free microbes lack vitality. Fungal Biol 122 (6):379-385.

doi:10.1016/j.funbio.2018.04.003

30. Walker GM, Basso TO (2019) Mitigating stress in industrial yeasts. Fungal Biology.

doi:https://doi.org/10.1016/j.funbio.2019.10.010

31. Yancey PH, Somero GN (1979) Counteraction of urea destabilization of protein structure by methylamine osmoregulatory compounds of elasmobranch fishes. Biochemical Journal 183 (2):317323. doi:10.1042/bj1830317

32. Eardley J, Dedi C, Dymond M, Hallsworth JE, Timson DJ (2019) Evidence for chaotropicity/kosmotropicity offset in a yeast growth model. Biotechnol Lett 41 (11):1309-1318. doi:10.1007/s10529-019-02737-8

33. Wang P-M, Zheng D-Q, Chi X-Q, Li O, Qian C-D, Liu T-Z, Zhang X-Y, Du F-G, Sun P-Y, Qu A-M, Wu $X-C$ (2014) Relationship of trehalose accumulation with ethanol fermentation in industrial Saccharomyces cerevisiae yeast strains. Bioresource Technology 152:371-376.

doi:https://doi.org/10.1016/j.biortech.2013.11.033

34. Mansure JJC, Panek AD, Crowe LM, Crowe JH (1994) Trehalose inhibits ethanol effects on intact yeast cells and liposomes. Biochimica et Biophysica Acta (BBA) - Biomembranes 1191 (2):309-316. doi:https://doi.org/10.1016/0005-2736(94)90181-3

35. Zhang L, Lang Y, Wang C, Nagata S (2008) Promoting effect of compatible solute ectoine on the ethanol fermentation by Zymomonas mobilis CICC10232. Process Biochemistry 43 (6):642-646. doi:https://doi.org/10.1016/j.procbio.2008.02.003

36. Takagi H (2008) Proline as a stress protectant in yeast: physiological functions, metabolic regulations, and biotechnological applications. Applied Microbiology and Biotechnology 81 (2):211223. doi:10.1007/s00253-008-1698-5 
37. Di Michele A, Freda M, Onori G, Santucci A (2004) Hydrogen Bonding of Water in Aqueous Solutions of Trimethylamine-N-oxide and tert-Butyl Alcohol: A Near-Infrared Spectroscopy Study. The Journal of Physical Chemistry A 108 (29):6145-6150. doi:10.1021/jp0494990

38. Fornili A, Civera M, Sironi M, Fornili SL (2003) Molecular dynamics simulation of aqueous solutions of trimethylamine- $\mathrm{N}$-oxide and tert-butyl alcohol. Physical Chemistry Chemical Physics 5 (21):4905-4910. doi:10.1039/B308248B

39. Mahipant G, Paemanee A, Roytrakul S, Kato J, Vangnai AS (2017) The significance of proline and glutamate on butanol chaotropic stress in Bacillus subtilis 168. Biotechnology for Biofuels 10 (1):122. doi:10.1186/s13068-017-0811-3

40. Bell AN, Magill E, Hallsworth JE, Timson DJ (2013) Effects of alcohols and compatible solutes on the activity of $\beta$-galactosidase. Appl Biochem Biotechnol 169 (3):786-794. doi:10.1007/s12010-0120003-3

41. Fox-Powell MG, Hallsworth JE, Cousins CR, Cockell CS (2016) lonic Strength Is a Barrier to the Habitability of Mars. Astrobiology 16 (6):427-442. doi:10.1089/ast.2015.1432

42. Yakimov MM, La Cono V, Spada GL, Bortoluzzi G, Messina E, Smedile F, Arcadi E, Borghini M, Ferrer M, Schmitt-Kopplin P, Hertkorn N, Cray JA, Hallsworth JE, Golyshin PN, Giuliano L (2015) Microbial community of the deep-sea brine Lake Kryos seawater-brine interface is active below the chaotropicity limit of life as revealed by recovery of mRNA. Environ Microbiol 17 (2):364-382. doi:10.1111/1462-2920.12587

43. de Lima Alves F, Stevenson A, Baxter E, Gillion JL, Hejazi F, Hayes S, Morrison IE, Prior BA, McGenity TJ, Rangel DE, Magan N, Timmis KN, Hallsworth JE (2015) Concomitant osmotic and chaotropicity-induced stresses in Aspergillus wentii: compatible solutes determine the biotic window. Curr Genet 61 (3):457-477. doi:10.1007/s00294-015-0496-8

44. Bhaganna P, Volkers RJ, Bell AN, Kluge K, Timson DJ, McGrath JW, Ruijssenaars HJ, Hallsworth JE (2010) Hydrophobic substances induce water stress in microbial cells. Microb Biotechnol 3 (6):701716. doi:10.1111/j.1751-7915.2010.00203.x

45. Casanova-Morales N, Alavi Z, Wilson CAM, Zocchi G (2018) Identifying Chaotropic and Kosmotropic Agents by Nanorheology. J Phys Chem B 122 (14):3754-3759.

doi:10.1021/acs.jpcb.7b12782 